\title{
Analysis of the comfort life and work in the assessment of the occupational group of employees in the energy sector on the basis of a mining company
}

\author{
Barbara Kowal $^{1 *}$ \\ ${ }^{1}$ AGH University of Science and Technology, Al. Mickiewicza 30, 30-059 Kraków, Poland
}

\begin{abstract}
There is a large number of jobs in Poland, the performance of which involves working in difficult, arduous conditions. Such jobs include probably the work of miners in hard coal mines. They often go to the mine several times a week for many years. They work several hundred meters underground in the dark, high temperature, humidity, dust and noise with loud machines. Such extreme working conditions cause many occupational diseases caused by these conditions and even life threatening. The total number of accidents in the whole mining has decreased at the turn of the last years, however, in the hard coal mining itself, it remains at a similar level. When performing work in such difficult conditions, the miner should know well and, above all, observe the work safety regulations. The appropriate organizational culture enables, among others shaping the level of safety culture and improving working conditions [2, 14, 19, 25, 26]. Therefore, miners should be constantly motivated to work safely, but also rewarded. The results of the literature analysis of the subject were supported by own research in the scope of the subject of comfort of life and work in the assessment of the professional group of energy sector employees on the example of a mining enterprise. The research was carried out among miners, in one of the Polish mines. They were intended to show the magnitude of the problem of discomfort in the work of a professional group of miners in hard coal mining, as well as comfort of life and motivation for a safe working mode.
\end{abstract}

\section{Introduction}

Polish hard coal mining remains a strategic branch of industry in Poland. The restructuring process going on in this industry, which involves the shutdowns and mergers of mines into coal companies, has brought about changes in their functioning and the working conditions of their employees $[9,17,18]$. Mine shutdowns have strongly contributed to a reduction in employment in an industry that has always been based on personnel as its most important organisational resource.

\footnotetext{
*Corresponding author: bkowal@agh.edu.pl,
} 
Considering the above, the industry should focus not only on tangible resources and financial results, or on finding ways to improve competitiveness, but also on intangible resources. It is social capital that is the major strategic resource for this industry [5]. Human resources contribute with knowledge, skills and dedication, and should be properly motivated to perform such difficult and dangerous work [14, 30, 32]. The appropriate range of incentives should be based on miners' current needs and expectations, which change over time, and depend on age and seniority [15]. Due to the specific conditions found in pits, the safety of miners' work represents a significant component of the social dimension of the strategies adopted by mining companies [7, 8, 20, 27, 28, 29].

Empirical studies conducted in Polish mines were aimed at drawing attention to the extremely difficult and adverse working conditions faced by miners. The results may be used in human resources management in Polish hard coal mining.

\section{Literature review}

There are extensive descriptions of the working conditions of miners in literature. In fact, these conditions are highly unpredictable, mainly due to the unforeseeable geological and mining conditions. Working in underground mines and pits involves potential exposure to a number of dangerous events, which may include fires, methane ignitions and explosions, coal dust explosions, cave-ins, rockbursts, machine failures, blast-media-related events, gas breakouts and rock outbursts. Not only do these events pose a significant threat when they occur, when the work accident appears [31, 34, 35], but they also lead to the development of a variety of occupational diseases in mining. Among the natural threats present in hard coal mines, in addition to the disease-causing threats, W. Konopko listed non-disease-causing threats [10]. Among the latter, he mentioned hazards related to health (dust, gas), climate and radiation, and other hazards [1, 6, 11, 12, 33]. In particular, hazards related to dust and gas can play a role in the said occupational diseases. They result from being exposed to hazardous events, or from staying in a loud, dusty, humid and dark environment with high temperatures. E. J. Sobczyk wrote that "hazards caused by high temperature in the pit can reduce the comfort of work performed underground" [23]. High temperatures, combined with high humidity, contribute to adverse climate conditions, which in turn lead to reduced human performance (i.e. reduced perception, attention span etc.), as described by N. Szlązak, A. Tor and A. Jakubów [27]. The climate conditions are influenced, i.a., by the thermodynamic parameters of inlet air, the properties of rocks surrounding the pit, the period of operating the pit and other factors [29]. These factors cannot be changed, and they are part of the specific geological and mining conditions.

According to the data from the Institute of Occupational Medicine, in 2013-2017 the total number of cases of occupational diseases among all miners (both active and former) was over two thousand, with pneumoconiosis responsible for the highest percentage (over $80 \%$ ) of all cases [37]. In 2017 a significant reduction in pneumoconiosis was observed among active hard coal mines. Fig. 1 presents specific incidence data. 


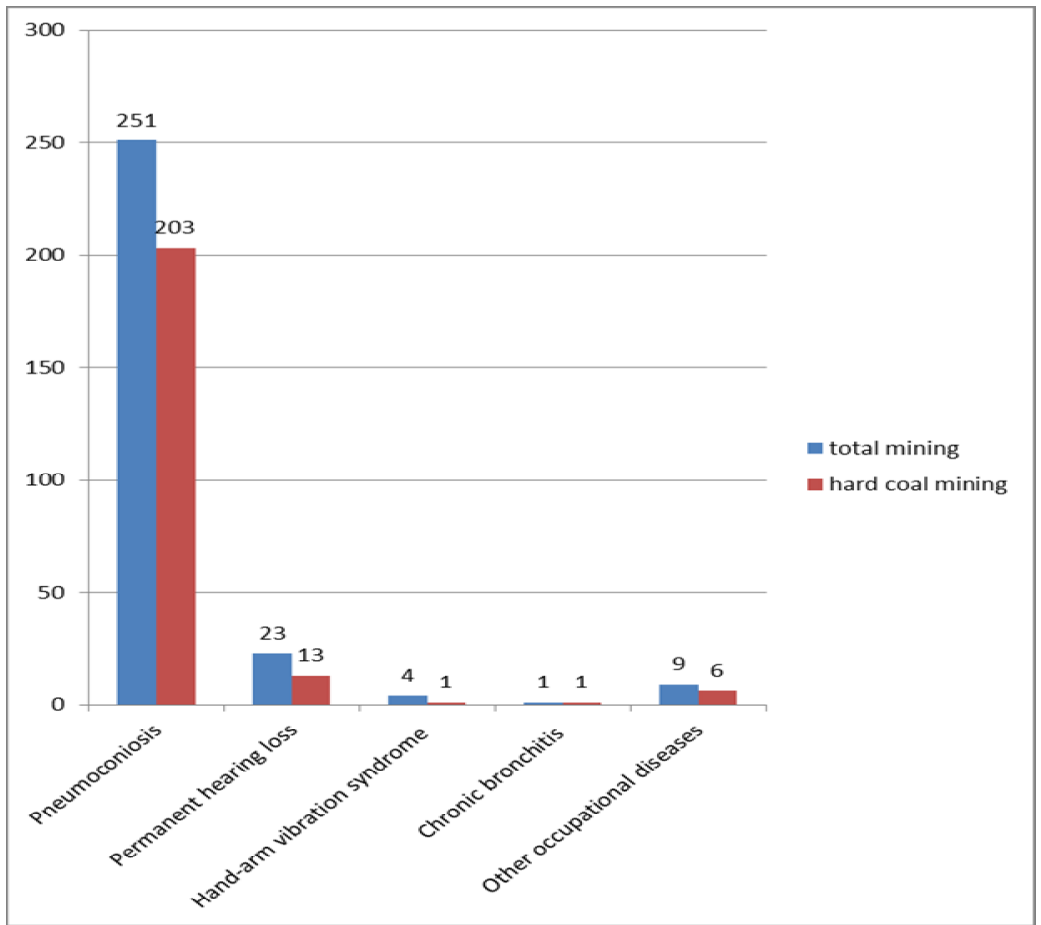

Fig.1. Incidence in hard coal mining in 2017. Own elaboration [38].

It should be noted that pneumoconiosis is more often diagnosed in former (retired) workers of hard coal mines than in professionally active miners (Fig. 2). This confirms that early preventive measures should be taken at work.

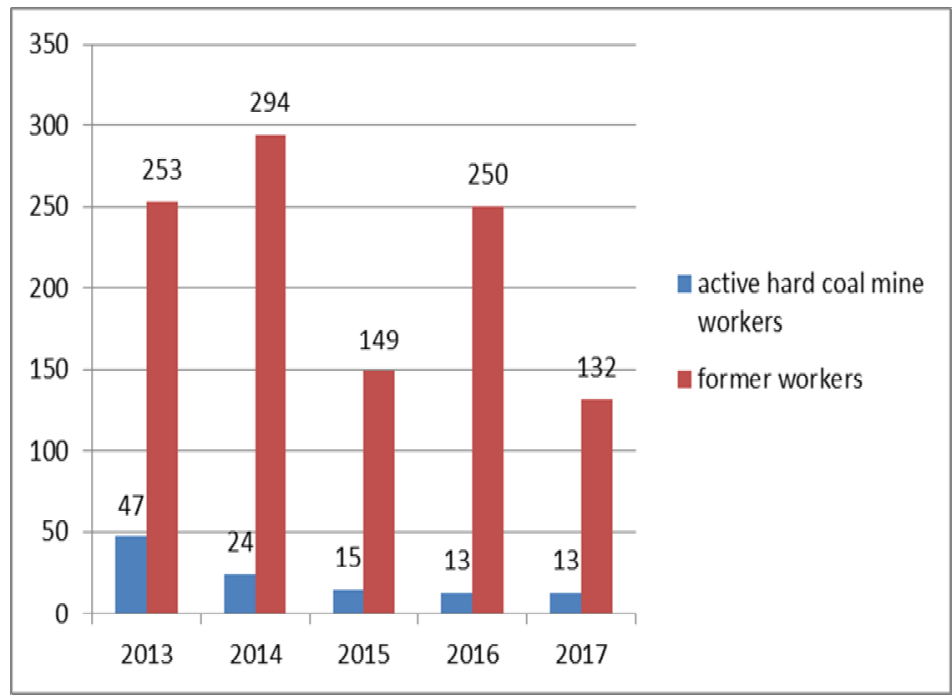

Fig.2. A comparison of the number of pneumoconiosis cases in former and active hard coal mine workers. Own elaboration [38]. 
In line with the concept adopted by Central Statistical Office Poland for measuring the quality of life, it is composed of multiple aspects. The report regarding the quality of life in Poland by thematic area, or the so-called domain indicative of the quality of life, in addition to financial conditions, education and personal safety, lists health [39]. Occupational diseases, such as pneumoconiosis, reduce the quality of life by adversely affecting physical performance and causing exercise-induced dyspnea, which lead to respiratory insufficiency [36]. However, a large number of cases are not diagnosed, as miners are not aware of the existence of this disease, are not covered by any screening programmes after leaving the job, or are not willing to pursue claims against their employer.

\section{Methods}

The survey sample consisted of people working in the energy sector, and in particular in the mining sector. The statistical sample of 115 people consisted of blue-collar workers from a Polish mine. In terms of seniority, the most numerous group of respondents was made up of people who have worked in the sector for up to 5 years (nearly $30 \%$ ), and from 5 to 10 years $(27 \%)$. The least numerous group was composed of people who have worked in the sector over thirty years (slightly more than $5 \%$ ).

The survey included:

- qualitative methods involving IDI - in-depth interviews with representatives of mines and mining companies, and with industry experts,

- quantitative methods.

The research objective of the survey was to obtain information on the quality of life and comfort at work of miners, and also to demonstrate the discomfort experienced at work by miners in hard coal mining, and the amounts of the bonuses and allowances due for work performed under harmful conditions.

\section{Results and discussion}

The study was divided into two parts: the first focuses on the quality of miners life, the second on their comfort at work.

The quality of life is mainly identified with relative employment stability, which provides sufficient funds. This is especially important when a miner provides for his family - his wife and children.

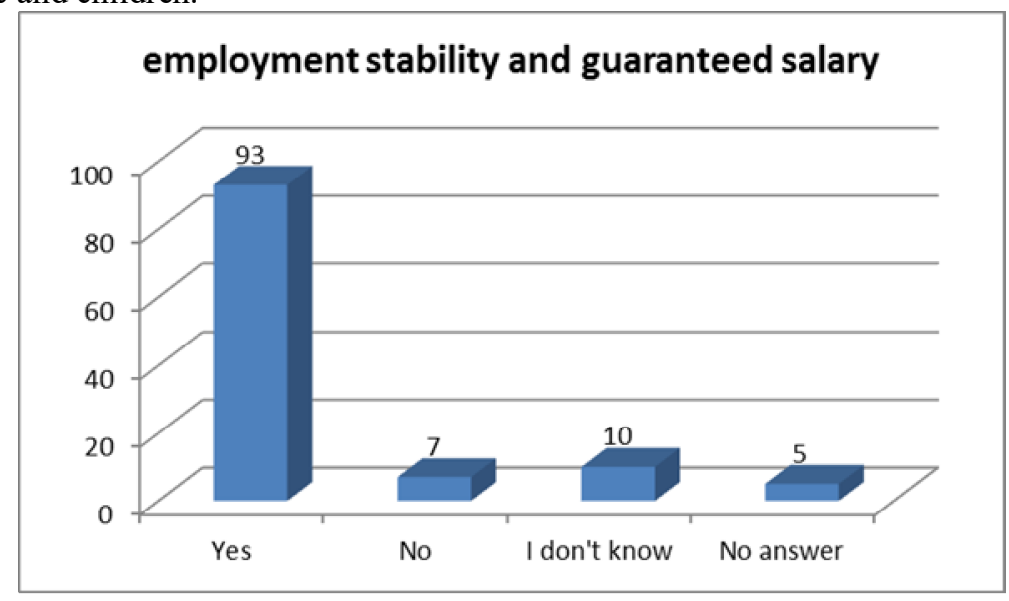

Fig.3. Determinants of comfort of life for miners. Own elaboration. 
This was the answer given by respondents when asked about what quality of life meant for them (Fig. 3) and why they started working in the mining sector (Fig. 4). Over $80 \%$ chose the following answer: "having stable employment and guaranteed salary" as a determinant of the quality of life. This group comprised 93 people from the whole survey sample. Seven respondents $(6 \%)$ declared that this response did not reflect the quality of life for them, and ten people (almost 9\%) were unsure about that. There were also 5 questionnaires (over 4\%) returned without any answer.

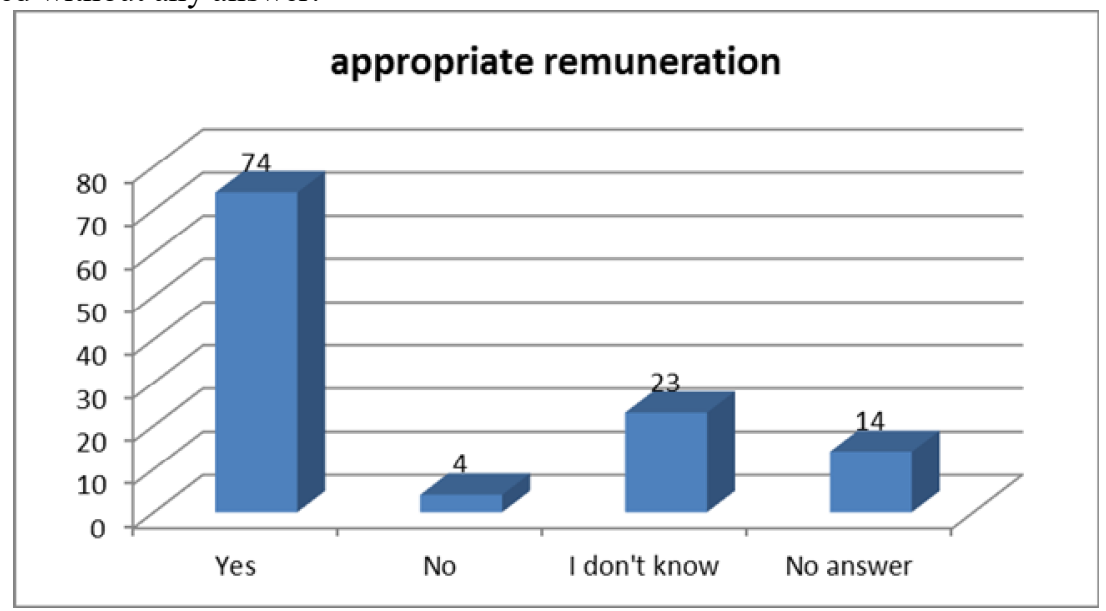

Fig.4. The most important factor contributing to taking up work in the mining sector. Own elaboration.

Over $64 \%$ of respondents (74 people) declared that they had chosen mining due to the appropriate level of remuneration that could be earned in that sector. Only 4 respondents argued that it was not the most important factor. 23 could not answer that question $(20 \%$ respondents) and 14 refused to respond.

The appropriate level of remuneration in mining is connected with a number of bonuses (in addition to the base salary) offered to miners. The bonuses assume the form of so-called privileges, which are reserved only for members of this profession and can be seen as indicative of belonging to this professional group [16, 21, 22]. Such bonuses (connected with the subject matter of this article) include overtime bonus and allowance for work under harmful, onerous and hazardous conditions. Miners receive additional remuneration for working overtime, which is "work performed in addition to the standard working time" [3]. Its amount is $50 \%$ of the hourly rate (depending on the position classification) for work during the two first overtime hours in a day - on weekdays, and $100 \%$ of the hourly rate during the next overtime hours and for working all overtime hours at night, on Sundays, holidays and other days off. 


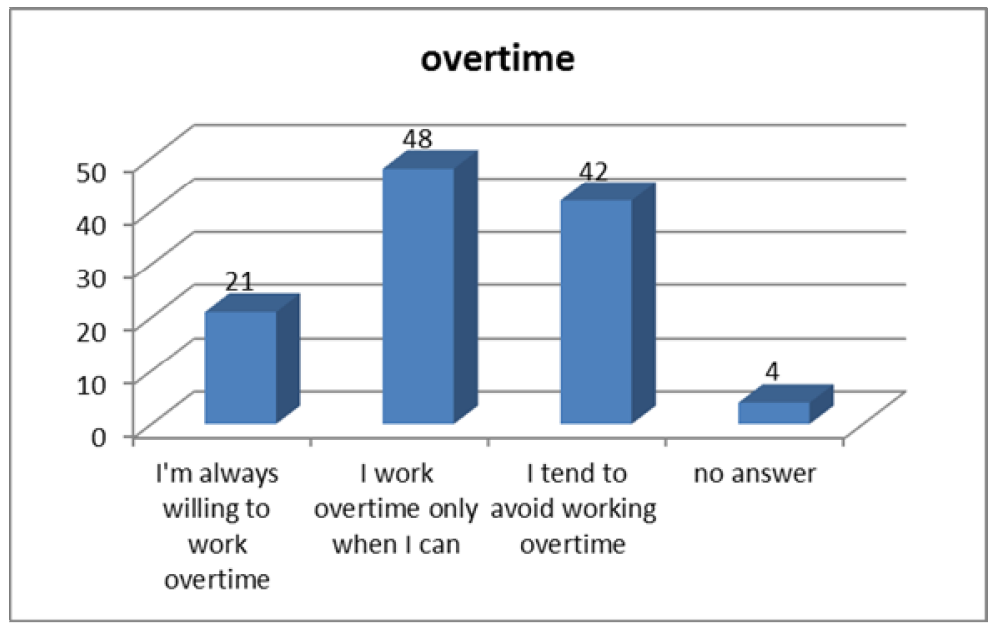

Fig.5. Responses to the question: "Do you often choose to work overtime?". Own elaboration.

Despite receiving additional remuneration for working overtime, not many miners decide to work overtime (Fig. 5) - only 21 respondents, i.e. a little over $18 \%$ of the miners, are willing to work overtime. As shown, the majority, i.e. 48 respondents, work overtime only when they can (about $42 \%$ of the survey sample), which means they would rather avoid it, and over $36 \%$ (as many as 42 respondents) tend to avoid overtime work completely. The height of the second additional remuneration for work under harmful, onerous and hazardous conditions might seem a little surprising, especially when we take into consideration the working conditions of miners, which are often highly unpredictable and hazardous to both their health and life. A lot of miners lost their colleagues or found themselves close to death when dangerous events occurred underground. It is even more understandable when we compare it with the amount of the second allowance mentioned, i.e. the allowance for work performed under harmful, onerous or dangerous conditions. For every hour worked under such conditions, miners are entitled to an allowance the amount of which is presented in Table 1. It is divided into four levels.

Tab.1. The amount of allowance for working under harmful, onerous and hazardous conditions.

Source: [3].

\begin{tabular}{|c|c|c|}
\cline { 2 - 3 } \multicolumn{1}{c|}{} & $\begin{array}{c}\text { \% of the remuneration } \\
\text { basis }\end{array}$ & $\begin{array}{c}\text { The height of the additional } \\
\text { remuneration per hour [PLN] }\end{array}$ \\
\hline Level 1 & $2 \%$ & 0,39 \\
\hline Level 2 & $3 \%$ & 0,59 \\
\hline Level 3 & $4 \%$ & 0,78 \\
\hline Level 4 & $5 \%$ & 0,98 \\
\hline
\end{tabular}

Due to the fact that every mine in Poland has its own Collective Labour Agreement, data regarding this allowance are presented in a number of different ways [3]. Such allowance is paid on the basis of lists of posts and department supervision records in relevant documents, which define the number of days (hours) worked under such conditions, along with the daily (hourly) rates. Although miners working underground are exposed to "noise, darkness, humidity, high temperatures, dust and constant awareness that this could be their last day at work," the amount of the allowance, which is meant to be a kind of compensation for "fatigue, dirt, sweat and constant risk," is difficult to ignore [36]. 
This and other allowances, or privileges, are meant to increase the attractiveness of this profession $[16,21,22]$.

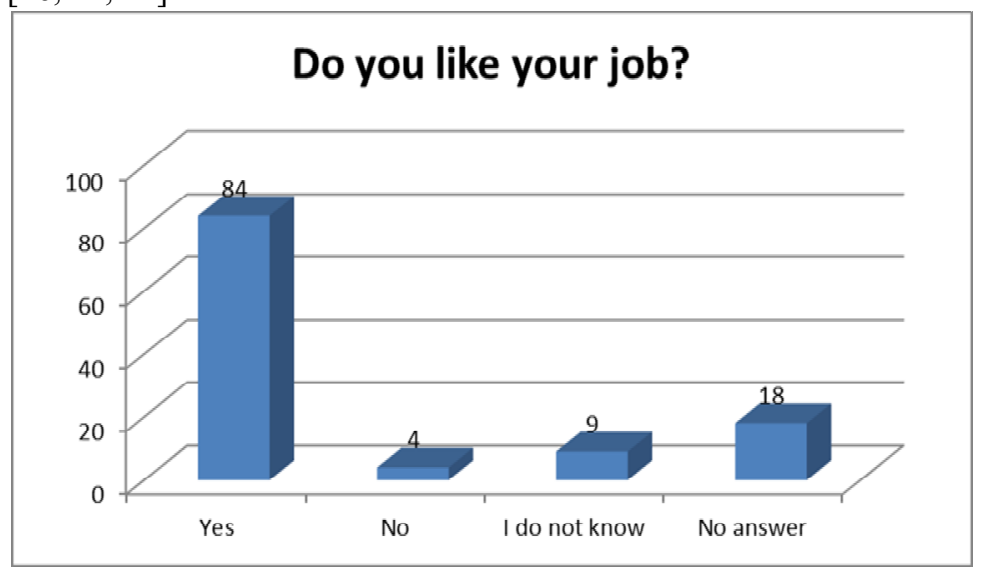

Fig.6. Responses to the question: "Do you like your job?". Own elaboration.

To quote an article published on the online portal wp.pl, "You either love or hate this job." With such small allowance per hour for working under hazardous conditions, it would seem that miners decide to take up such work only because of the basic salary offered by the industry. However, $73 \%$ of respondents in the survey said that they liked their job (Fig. 6). To compare with the remaining answers, 4 respondents did not like their job and 9 could not state whether they liked it or not, while 18 refused to answer (it would be interesting to find out why). It can thus be concluded that those 84 miners are really fond of their job.

This is confirmed in another question: "Are you attached to your workplace?" (responses shown in Fig. 7).

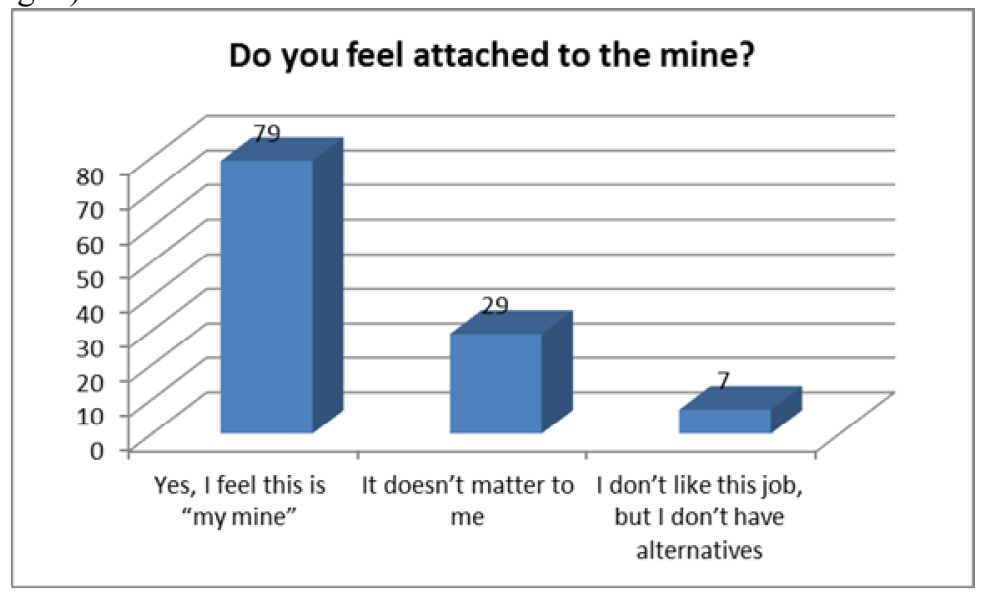

Fig.7. Responses to the question: "Do you feel attached to the mine?". Own elaboration.

Out of the said 115 respondents who declared that they liked their job, as many as 79 (nearly $69 \%$ of all) feel a strong attachment to their workplace (Fig. 7). They "feel that it is their mine" that means they identify with the mine and feel attached to it. The remaining respondents, over $25 \%$, declared that they had no feelings in relation to the mine, and $6 \%$ said they did not like their job. 
In fact, in the case of the mining industry and the work of miners in underground mines, at development and working faces, their comfort at work (and particularly the working conditions) are connected with the quality of life, especially in terms of health. In the surveyed group of 115 respondents, 33\% (38 respondents) declared that they needed regular, and even additional, medical care (Fig. 8). Due to performing work underground, in temperatures of up to 30 centigrade, in dusty and humid conditions, and in the presence of vibrating and loud machines, miners are prone to numerous diseases, as mentioned before.

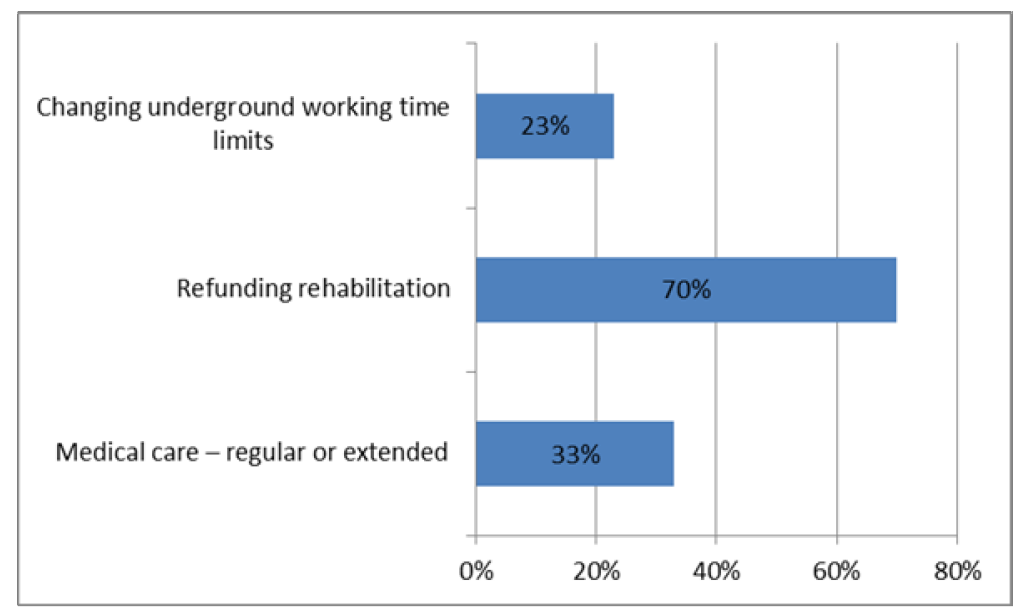

Fig.8. Responses to the question: "What are your needs with regard to your work at the mine?". Own elaboration.

Miners realise that some of those diseases are only discovered after many years and carry certain risks. For this reason, the vast majority of the surveyed group, i.e. $70 \%(81$ respondents) reported the need for rehabilitation to be refunded. These respondents are aware of the potential consequences of working in mining industry. Perhaps they were among those who got injured at work and would like to take part in preventive exercise programmes, rehabilitation procedures and massages.

Furthermore, it should be pointed out that they also need and expect changes to the current working time regulations for miners. This was pointed out by 26 people, i.e. $33 \%$ of the survey sample.

In summarising and comparing the quality of life of miners with their comfort at work, it should be noted that theirs occupation is a high-risked. Due to the difficult conditions at work, coupled with a variety of related inconveniences and health problems, as injuries to lower limbs caused by uncomfortable work shoes [4, 24], as well as the eventual onset of occupational diseases and, most importantly, the unpredictable nature of geological and mining conditions, it should be concluded that miners experience discomfort, rather than comfort, at work. The survey shows that the respondents are aware of this situation, but they also value employment stability and higher salaries which help them ensure a decent quality of life.

\section{Conclusion}

Miners, who work in such difficult conditions, should know well the all principles of Occupational Safety and Hygiene and always follow their rules $[8,13]$. For this reason, miners should be constantly motivated to perform their work in a safe manner. Various privileges, which increase the attractiveness of this occupation, may serve as an incentive. 
These include the allowance for work performed under harmful, onerous and dangerous conditions.

The purpose of demonstrating the scale of the problem, that is the discomfort experienced at work by miners in hard coal mining, was to point out that the height of the additional remuneration for work under harmful, onerous and hazardous conditions as component of remuneration is rather low.

Social capital is a strategic resource of mining companies [5]. Given the fact that the concentration of mining operations, which involves working at greater depths, has become the industry's goal, a solution should be sought to motivate miners to perform their work in a safe manner. This is even more important when we consider the significantly more adverse climate conditions found in lower layers.

The results of the studies may be used in human resources management in Polish hard coal mining. It is impossible to hide that the wage is the main element shaping the life of miners, which is why changes in the remuneration and incentive systems should be considered, e.g. in the form of special rates for working under harmful conditions.

This paper was prepared as a part of research studies conducted the AGH University of Science and Technology [No. 11.11.100.693].

\section{References}

1. P. Bąk, M. Sukiennik, M. Kapusta, The role of health and safety at work in the mining company, [in Polish], Przegląd Górniczy 72, 8, 11-15 (2016)

2. P. Bąk, M. Sukiennik, B. Kowal, Corporate culture in terms of management processes in the Polish mining companies, [in Polish] Journal of the Polish Mineral Engineering Society 17, 2, 135-144, (2016)

3. Collective Labour Agreements in force at mines

4. J.A. Dobson, D.L. Riddiford-Harland, A.F. Bell, J.R. Steele, Are underground coal miners satisfied with their work boots?, DOI: 10.1016/j.apergo.2017.08.009, Applied Ergonomics 66, 98-104 (2018)

5. S. Jarosławska-Sobór, Social potential growth of a mining company on the basis of human capital and occupational safety, Journal of Sustainable Mining, Journal of Sustainable Mining 14, 4, 195-202 (2015)

6. I. Jonek-Kowalska, Corporate Social Responsibility and restructuring of mining enterprises in Poland, In: Around the basic issues of modern times. (ed.) Aleksandra Kuzior. Interdisciplinary Theoretical and Empirical Studies 2 [in Polish],. (Zabrze, 2017)

https://www.polsl.pl/organizacje/SCEBIZR/Documents/Kuzior\%20Aleksandra\%20\%20Etyka\%202\%202017.pdf

7. M. Kapusta, Impact of Mining Executives on Improving Occupational Safety and Health, [in Polish] Journal of the Polish Mineral Engineering Society 18, 2, 183-193 (2017)

8. M. Kapusta, M. Sukiennik, P. Bąk, Effectiveness of Occupational Health and Safety Rules in Shaping Organizational Culture, Journal of the Polish Mineral Engineering Society 20, 1, 245-254 (2018)

9. A. Karbownik, Coal mining in Poland. Assessment of the current state (ed. H. Bochniarz S. Krajewski) Sectoral restructuring programs and privatization of state assets. Selection of expertise [in Polish], 1997.

10. W. Konopko, Natural hazards in hard coal mines - current state and trend of changes. [in Polish] (Conference materials at the Underground Mining School, Kraków, 2006) 
11. W. Konopko (ed.), Work safety in hard coal mines, [in Polish] (Publisher of the Central Mining Institute, Katowice, 2013).

12. W. Konopko (ed.), Annual report on the status of basic natural and technical hazards in hard coal mining, [in Polish] (Publisher of the Central Mining Institute, Katowice, 2014)

13. B. Kowal, R. Ranosz, M. Karkula, D. Kowal, Process Management in Hard Coal Mining Companies, http://doi.org/10.29227/IM-2018-02-14. Journal of the Polish Mineral Engineering Society 20, 2, 111-116 (2018),

14. B. Kowal, Key performance indicators in a multi-dimensional performance card in the energy sector, DOI: 10.1088/1755-1315/214/1/012093, IOP Conf. Series: Earth and Environ. Sci. 214, 012093 (2019).

15. B. Kowal, An analysis of the expectations of an occupational group of miners based on the example of Polish mining, 5th International Multidisciplinary Scientific Conference on SOCIAL Sciences and Arts, Bulgaria. DOI: 10.5593/sgemsocial2018/1.5/S05.007 Conference proceedings, Vol. 5, Modern science, issue 1.5, Business and management, 5, 55-62 (2018)

16. B. Kowal, The entitlements of production workers based on the example of Polish mining, 5th International Multidisciplinary Scientific Conference on SOCIAL Sciences and Arts, Bulgaria. DOI: 10.5593/sgemsocial2018/1.5/S05.152 Conference proceedings. Vol. 5, Modern science, issue 1.5, Business and management, 5, 1225$1232(2018)$

17. A. Manowska, A. Rybak, Analysis of employment in the mining sector taking into account the forecasted demand for hard coal, 4th International Multidisciplinary Scientific Conference on Social Sciences and Arts, Bulgaria, DOI: 10.5593/sgemsocial2017/15/S05.010 Conference proceedings. Book 1, Modern science. Vol. 5, Business and management, 5, 75-82 (2017)

18. A. Manowska, A. Rybak, The future of hard coal compared to other energy carriers, 4th Polish Mining Congress, IOP Conf. Series: Earth and Environ. Sci. 174, 012007 (2018)

19. R. Ogrodnik, Environmental performance indicators of hard coal mine, DOI: 10.1088/1755-1315/214/1/012084 IOP Conf. Series: Earth and Environ. Sci. 214, 012084 (2019)

20. M. Podobińska-Staniec, Employee training system as a form of intellectual capital development in mining companies, [in Polish], Journal of the Polish Mineral Engineering Society, 18, 2, 265-270 (2017)

21. A. Przybyłka, Privileges related to work in mining - in the past and today, [in Polish] Science notebooks in Katowice 78, 169-179, (2011)

22. A. Przybyłka A., Privileges related to mining work compared to other professional groups, in: Determinants of the modern labor market and their effects in the socioeconomic sphere, (ed. Kotlorz D., Przybyłka A.), [in Polish], Science notebooks 196, 196-207 (2014)

23. E.J. Sobczyk, Arduousness of hard coal mining and geologic condotions and their influence on resources management, (Mineral and Energy Economy Research Institute of the Polish Academy of Sciences, ISBN 978-83-60195-07-9, Kraków, 2009)

24. E.J. Sobczyk, M. Kopacz, Assessing geological and mining condition nuisance and its impact on the cost of exploitation in hard coal mines with the use of a multi-criterion method, DOI 10.24425/123690, Arch. Min. Sci. 63, 3, 665-686 (2018)

25. M. Sukiennik, P. Bąk, M. Kapusta, Corporate Culture and the Human Factor in the Polish Mining Companies, [in Polish], Journal of the Polish Mineral Engineering Society 17, 2, 125-134 (2016) 
26. M. Sukiennik, P. Bąk, Corporate culture versus CSR in Polish companies of the energy sector, DOI: 10.1088/1755-1315/214/1/012075. IOP Conf. Series: Earth and Environ. Sci. 214, 1, 012075 (2019)

27. N. Szlązak, A. Tor, A. Jakubów, Methods of combating the temperature threat in the mines of the Jastrzębska Spótka Weglowa, (Library of school underground exploitation IGSMiE PAN Publishers, Cracow, 2006)

28. J. Szlązak, N. Szlązak, Occupational Health and Safety, [in Polish], (AGH publishing, Cracow, 2010)

29. N. Szlązak, D. Obracaj, M. Borowski, Methods of combating temperature risk in Polish hard coal mines. Mining and Environment. GiG research papers, I (IGSMiE PAN, Cracow, 2007)

30. K. Tobór-Osadnik, M. Wyganowska, J. Korski, A. Manowska, Identification of stimuli motivating workers to follow occupational health and safety (OHS) regulations on the examples of polish hard coal mines. 3rd International Multidisciplinary Scientific Conference on Social Sciences and Arts, SGEM ,poz. 10.5593/SGEMSOCIAL2016/B12/S02.075 Conference proceedings. Book 1, Psychology \& psychiatry, sociology \& healthcare, education. Vol. 2, Sociology and healthcare 2, 581-588 (2016)

31. S. Ural, S. Demirkol, Evaluation of occupational safety and health in surface mines, https://doi.org/10.1016/j.ssci.2007.11.010, Safety Science, 46, 6, 1016-1024 (2008)

32. D. Wandzich, B. Walkiewicz B., G. Płaza, The role of motivating factors in the professional group of miners, [in Polish], Scientific notebooks of the Silesian University of Technology, series: Organization and Management 71, 1917, 305-314 (2014)

33. K. Wodarski, M. Popczyk, Natural hazards as a source of operational risk in a mining enterprise, [In:] Operational risk management in a mining enterprise, (ed.) Izabela Jonek-Kowalska \& Marian Turek, [in Polish], (PWN, Warszawa, 2011)

34. M. Wyganowska, A study of the correlation between age and the number of work accidents in mining enterprises between 2003-2017, Journal of the Polish Mineral Engineering Society 19, 2, 81-86 (2018)

35. [online] [2018.07.02] http://www.wug.gov.pl/bhp/zdarzenia

36. [on line] [2018.08.30] A miner's work often costs him his health and even life, www.wp.pl

37. [on line] [2018.08.25] An assessment of the status of work safety, mine rescue and public security in connection with mining and geological operations in 2017 (comparison from 2013), https://wug.bip.info.pl/dokument.php?iddok=336\&idmp=26\&r=r

38. [on line] [2018.09.19] State Mining Authority - OHS Status, http://www.wug.gov.pl/bhp/stan_bhp_w_gornictwie

39. [on line] [2018.09.19] Statistics Poland „Quality of life in Poland" 2017 Edition”, https://stat.gov.pl/files/gfx/portalinformacyjny/pl/defaultaktualnosci/5486/16/4/1/jakos c_zycia_w_polsce_2017.pdf 